\title{
Response of $\mathrm{Gd}_{2} \mathrm{Ti}_{2} \mathrm{O}_{7}$ and $\mathrm{La}_{2} \mathrm{Ti}_{2} \mathrm{O}_{7}$ to swift-heavy ion irradiation and annealing
}

Sulgiye Park ${ }^{\mathrm{a}}$, Maik Lang ${ }^{\mathrm{b}}$, Cameron L. Tracy ${ }^{\mathrm{c}}$, Jiaming Zhang ${ }^{\mathrm{a}}$, Fuxiang Zhang ${ }^{\mathrm{d}}$, Christina Trautmann $^{\mathrm{e}, \mathrm{f}}$, Matias D. Rodriguez ${ }^{\mathrm{g}}$, Patrick Kluth ${ }^{\mathrm{g}}$, Rodney C. Ewing ${ }^{\mathrm{a}, *}$

${ }^{a}$ Geological and Environmental Sciences, Stanford University, Stanford, CA, 94305, USA

${ }^{\mathrm{b}}$ Department of Nuclear Engineering, University of Tennessee, TN, 37996, USA

${ }^{c}$ Department of Materials Science and Engineering, University of Michigan, Ann Arbor, MI 48109, USA

${ }^{\mathrm{d}}$ Department of Earth and Environmental Sciences, University of Michigan, Ann Arbor, MI 48109, USA ${ }^{\circ}$ GSI Helmholtzzentrum für Schwerionenforschung, 64291 Darmstadt, Germany

${ }^{\mathrm{f}}$ Technische Universität Darmstadt, 64287 Darmstadt, Germany

${ }^{\mathrm{g}}$ Department of Electronic Materials Engineering, Research School of Physics and Engineering, Australian National University, Canberra ACT 2601, Australia

*corresponding author: rewing1@ @stanford.edu

\begin{abstract}
Swift heavy ion $\left(2 \mathrm{GeV}^{181} \mathrm{Ta}\right)$ irradiation-induced amorphization and temperature-induced recrystallization of cubic pyrochlore $\mathrm{Gd}_{2} \mathrm{Ti}_{2} \mathrm{O}_{7}(F d \overline{3} m)$ are compared with the response of a compositionally-similar material with a monoclinic-layered perovskite-type structure, $\mathrm{La}_{2} \mathrm{Ti}_{2} \mathrm{O}_{7}$ $\left(P 2_{1}\right)$. The averaged electronic energy loss, $d E / d x$, was $37 \mathrm{keV} / \mathrm{nm}$ and $35 \mathrm{keV} / \mathrm{nm}$ in $\mathrm{Gd}_{2} \mathrm{Ti}_{2} \mathrm{O}_{7}$ and $\mathrm{La}_{2} \mathrm{Ti}_{2} \mathrm{O}_{7}$, respectively. Systematic analysis of the structural modifications was completed using transmission electron microscopy, synchrotron X-ray diffraction, Raman spectroscopy, and small-angle X-ray scattering. Increasing ion-induced amorphization with increasing ion fluence was evident in the X-ray diffraction patterns of both compositions by a reduction in the intensity of the diffraction maxima concurrent with the growth in intensity of a broad diffuse scattering
\end{abstract}


halo. Transmission electron microscopy analysis showed complete amorphization within ion tracks (diameter: $\sim 10 \mathrm{~nm}$ ) for the perovskite-type material; whereas a concentric, core-shell morphology was evident in the ion tracks of the pyrochlore, with an outer shell of disordered yet still crystalline material with the fluorite structure surrounding an amorphous track core (diameter: $\sim 9 \mathrm{~nm}$ ). The radiation response of both titanate oxides with the same stoichiometry can be understood in terms of differences in their structures and compositions. While the radiation damage susceptibility of pyrochlore $\mathrm{A}_{2} \mathrm{~B}_{2} \mathrm{O}_{7}$ materials decreases as a function of the cation radius ratio $r_{A} / r_{B}$, the current study correlates this behavior with the stability field of monoclinic structures, where $\mathrm{r}_{\mathrm{La}} / \mathrm{r}_{\mathrm{Ti}}>\mathrm{r}_{\mathrm{Gd}} / \mathrm{r}_{\mathrm{Ti}}$. Isochronal annealing experiments of the irradiated materials showed complete recrystallization of $\mathrm{La}_{2} \mathrm{Ti}_{2} \mathrm{O}_{7}$ at $775{ }^{\circ} \mathrm{C}$ and of $\mathrm{Gd}_{2} \mathrm{Ti}_{2} \mathrm{O}_{7}$ at $850{ }^{\circ} \mathrm{C}$. The annealing behavior is discussed in terms of enhanced damage recovery in $\mathrm{La}_{2} \mathrm{Ti}_{2} \mathrm{O}_{7}$, compared to the pyrochlore compounds $\mathrm{Gd}_{2} \mathrm{Ti}_{2} \mathrm{O}_{7}$. The difference in the recrystallization behavior may be related to structural constraints, i.e., reconstructing a low symmetry $v$ s. a high symmetry phase.

\section{INTRODUCTION}

The $\mathrm{A}_{2} \mathrm{~B}_{2} \mathrm{O}_{7}$ pyrochlore structure has been investigated for various technological applications, such as a nuclear wasteform for actinide immobilization, electrolytes for solid oxide fuel cells, and thermal barrier coatings for gas turbines [1-4]. The wide variety of pyrochlore compositions ( 450 synthetic compositions) results in widely varying chemical and physical properties, as well as its structural diversity, resulting from the different combinations of $A$ - and $B$ - site cations [5,6]. Pyrochlores are structurally isometric $(F d \overline{3} m, \mathrm{Z}=8, \mathrm{a}=0.9-1.2 \mathrm{~nm})$, and can be described as an anion-deficient derivative of the fluorite structure, $\mathrm{AX}_{2}(F m \overline{3} m)$, with one-eighth of the anions removed and two types of cations ordered on the A- and B-sites [6,7]. The stability of the pyrochlore structure is determined by the cationic radius ratio $r_{\mathrm{A}} / \mathrm{r}_{\mathrm{B}}$. At ambient conditions, the 
stable pyrochlore structure $(F d \overline{3} m)$ is formed for those with $\mathrm{r}_{\mathrm{A}} / \mathrm{r}_{\mathrm{B}}$ of $1.46-1.78$. If the $\mathrm{r}_{\mathrm{A}} / \mathrm{r}_{\mathrm{B}}$ drops below 1.46, a disordered fluorite structure $(F m \overline{3} m)$, forms, and when it is above 1.78 , such as when La occupies the A-site and Ti occupies the B-site, the structure conforms to a monoclinic, layered-perovskite structure $\left(P 2_{1}\right)$, which belongs to a homologous series $\mathrm{A}_{n} \mathrm{~B}_{n} \mathrm{O}_{3 n+2}$ where $n=4$ [8]. Fig. 1 shows the crystal structures of $\mathrm{Gd}_{2} \mathrm{Ti}_{2} \mathrm{O}_{7}$ and $\mathrm{La}_{2} \mathrm{Ti}_{2} \mathrm{O}_{7}$ projected along the [010] direction. The perovskite, $\mathrm{La}_{2} \mathrm{Ti}_{2} \mathrm{O}_{7}$, contains alternating layers of corner-sharing $\mathrm{TiO}_{6}$ octahedra: a layer with corner-sharing $\mathrm{TiO}_{6}$ bridged with La cations is topped with corner-sharing $\mathrm{TiO}_{6}$, with La cations located in the interstices between the two octahedra. Within a single unit cell, the two layers are periodically repeated with $\beta=98.60^{\circ}$, forming a monoclinic-layered perovskite structure.

The structural response of pyrochlore-structured complex oxides and related phases to highenergy heavy ion irradiation is of significant interest, due to the applications of these materials as wasteforms for the immobilization and disposal of radionuclides. In order to understand compositional and structural influences on radiation effects, extensive ion-beam irradiation studies using various ion species and energies have been completed on a wide variety of $\mathrm{A}_{2} \mathrm{~B}_{2} \mathrm{O}_{7}$ compositions [9-17]. Irradiation experiments with swift heavy ions of initial energies in the range of $\mathrm{MeV}$ to $\mathrm{GeV}$, which deposit energy into a material mainly through electronic excitation and are useful for simulating the effects of nuclear fission fragment irradiation, were mainly performed on titanate and zirconate pyrochlores [9-12]. These studies emphasize that the radiation tolerance of pyrochlores is proportional to $\mathrm{r}_{\mathrm{A}} / \mathrm{r}_{\mathrm{B}}$, and that tolerant materials show disordering to a fluorite structure rather than amorphizing under irradiation. In the present work, we report the effects of swift heavy ion irradiation and high temperature on the perovskite compound, $\mathrm{La}_{2} \mathrm{Ti}_{2} \mathrm{O}$, for comparison to their effects on the pyrochlore compound, $\mathrm{Gd}_{2} \mathrm{Ti}_{2} \mathrm{O}_{7}$, in 
order to understand how structures affect these closely related compositions. The two compounds find applications in a variety of areas. $\mathrm{Gd}_{2} \mathrm{Ti}_{2} \mathrm{O}_{7}$ has been proposed as an actinide nuclear wasteform [1,3]. Most applications of $\mathrm{La}_{2} \mathrm{Ti}_{2} \mathrm{O}_{7}$ are due to its electrical properties, photocatalytic activity, photoluminescence, high-temperature piezoelectric nanostructures with its high Curie temperature $\left(\mathrm{T}_{\mathrm{c}}=1500{ }^{\circ} \mathrm{C}\right)$, and low dielectric constant $\left(\varepsilon_{\mathrm{r}}=42-62\right)$, making the material a multifunctional candidate [18-20]. This paper presents a detailed investigation of swift heavy ion irradiation damage and annealing behavior in the monoclinic-layered perovskite $\mathrm{La}_{2} \mathrm{Ti}_{2} \mathrm{O}_{7}$ and cubic $\mathrm{Gd}_{2} \mathrm{Ti}_{2} \mathrm{O}_{7}$ pyrochlore. The two compounds' response to irradiation and temperature is discussed in terms of ionic sizes of the cations, topology and thermodynamic stability.

\section{EXPERIMENTAL}

Polycrystalline samples of $\mathrm{Gd}_{2} \mathrm{Ti}_{2} \mathrm{O}_{7}$ and $\mathrm{La}_{2} \mathrm{Ti}_{2} \mathrm{O}_{7}$ were synthesized by a sol-gel method, the details of which have been reported elsewhere [21]. The typical grain size of the samples was several microns, and the measured densities of $\mathrm{Gd}_{2} \mathrm{Ti}_{2} \mathrm{O}_{7}$ and $\mathrm{La}_{2} \mathrm{Ti}_{2} \mathrm{O}_{7}$ were $6.56 \mathrm{~g} / \mathrm{cm}^{3}$ and $5.82 \mathrm{~g} / \mathrm{cm}^{3}$, respectively. The dense pellets were polished (roughness: $\leq 1 \mu \mathrm{m}$ ) without specific orientation down to a thickness of $\sim 40 \mu \mathrm{m}$ and subsequently annealed at $800{ }^{\circ} \mathrm{C}$ for 24 hours to evaporate absorbed water. Samples were than cut into small pieces with an area of $\sim 0.25 \mathrm{~cm}^{2}$ for irradiation. The ion irradiation experiment was performed at the beamline $\mathrm{X} 0$ of the UNILAC linear accelerator (GSI Helmholtz Center) in Darmstadt, Germany. At room temperature under vacuum, all samples were entirely exposed to a defocused $\mathrm{cm}$-sized ${ }^{181} \mathrm{Ta}$ beam with an ion energy of $2.0 \mathrm{GeV}$. These energetic particles travel through solids in a roughly linear manner, producing high aspect ratio, cylindrical "ion tracks" of damage material, typically several nanometers in diameter and tens of micrometers in length. This damage can be considered a result of rapid heating of the material inside an ion track through energy deposition to its 
electrons, which can result in local melting and subsequent quenching as this thermal energy is conducted radially outwards from the track core. The projected range of the projectiles, as calculated using the SRIM 2008 code [22], for $\mathrm{Gd}_{2} \mathrm{Ti}_{2} \mathrm{O}_{7}$ and $\mathrm{La}_{2} \mathrm{Ti}_{2} \mathrm{O}_{7}$ are approximately $58 \mu \mathrm{m}$ and $62 \mu \mathrm{m}$, respectively. This is about $20 \mu \mathrm{m}$ larger than the entire sample thickness, indicating that all impinging ions passed completely through the sample (Fig. 2). The averaged electronic energy loss, $d E / d x$, in the $\mathrm{Gd}_{2} \mathrm{Ti}_{2} \mathrm{O}_{7}$ sample was $37 \mathrm{keV} / \mathrm{nm}$ and in $\mathrm{La}_{2} \mathrm{Ti}_{2} \mathrm{O}_{7}, 35 \mathrm{keV} / \mathrm{nm}$. The nuclear energy loss is neglected because it is about three orders of magnitude less than the electronic energy loss. The two sets of samples were prepared and irradiated to different fluences between $1 \times 10^{10}$ and $1 \times 10^{13}$ ions $/ \mathrm{cm}^{2}$. The typical uncertainty for the absolute fluence value of a specific irradiation experiment is $10-20 \%$. Because both samples were, for a given fluence, simultaneously irradiated and the fluence series were completed with identical beam settings, the relative error in fluence is minimal. Isochronal annealing experiments were completed by heating the samples in the furnace. The samples were irradiated to a maximum fluence of $10^{13}$ ions $/ \mathrm{cm}^{2}$, which assured complete amorphization.

Following irradiation, to a fluence of $1 \times 10^{13}$ ions $/ \mathrm{cm}^{2}$, at which point the entire sample volume had been modified by ion impact, samples were annealed from $500^{\circ} \mathrm{C}$ to $850^{\circ} \mathrm{C}$, in increments of $50^{\circ} \mathrm{C}$. The samples were rapidly heated in a furnace in air to the desired temperature, then held for 15 minutes at each temperature increment and subsequently cooled for 15 minutes before each measurement. The two compounds were annealed simultaneously.

Samples before and after irradiation and annealing were characterized by angledispersive synchrotron powder X-ray diffraction measurements (XRD) performed at the beam line B2 of the Cornell High Energy Synchrotron Source (CHESS) of Cornell University. A mono-energetic beam of $25 \mathrm{keV}(\lambda=0.496 \AA)$ with spot size of $\sim 1 \mathrm{~mm}$ was used in transmission 
mode to analyze ion-induced structural modifications throughout the entire sample. Debye diffraction rings were recorded with a Mar CCD detector, and the integrated one-dimensional patterns were produced with the Fit 2D software [23], after which the software Fullprof [24] was used for Rietveld refinement of the diffraction patterns. The ion-induced amorphization was then quantified by deconvolution of the diffraction peaks in order to differentiate diffraction intensity contributions from the crystalline and amorphous fractions, respectively. The integrated intensities of diffraction maxima were used to deduce the phase fractions with a peak-fitting procedure (Pseudo-Voigt profiles), which is described in detail elsewhere [25].

Amorphized and partially amorphized samples were studied ex situ using transmission electron microscopy (TEM) that was performed on a JEOL 3011 and FEI Titan aberrationcorrected TEM. Bright-field and high-resolution images, as well as electron diffraction patterns were obtained for samples irradiated with $2.0 \mathrm{GeV}$ Ta ions at a low fluence of $1 \times 10^{11}$ ions $/ \mathrm{cm}^{2}$, where neighboring tracks are well-separated. For bright field images, the irradiated samples were crushed into a fine powder and deposited on a holey carbon TEM grid. For the HRTEM imaging, the irradiated samples were thinned using mechanical polishing to $\sim 40 \mu \mathrm{m}$ and subsequent ion milling until the sample was electron-transparent. Fast Fourier transform (FFT) analyses were performed on the two compounds to detect the internal and surrounding structure of the tracks. The track diameters were measured from both the bright-field images and high-resolution TEM (HRTEM) images.

Transmission small-angle X-ray scattering (SAXS) measurements were performed at the Australian Synchrotron at the Australian National University on the samples irradiated to $5 \times$ $10^{11}$ ions $/ \mathrm{cm}^{2}$, at which point ion tracks were spatially-separated. Isochronal annealing was performed between $500^{\circ} \mathrm{C}$ and $940^{\circ} \mathrm{C}$. The samples were rapidly heated to each increment 
temperature and annealed in a furnace in air for $30 \mathrm{~min}$, and measured both at room temperature before annealing and between annealing steps. The X-ray energy was $11 \mathrm{keV}(\lambda=1.127 \AA)$. Data were collected using a Pilatus $1 \mathrm{M}$ detector for a q-range of $0.01<\mathrm{q}<0.4 \AA^{-1}$. The sample was placed on a 3-axis goniometer that allowed the sample to be tilted, and the SAXS images were taken with the track axes oriented between $0^{\circ}$ and $10^{\circ}$ with respect to the X-ray beam direction. The scattering data was analyzed by modeling the tracks as cylindrical objects where the best fits where achieved assuming a constant mass density in the track. Deviations from perfect cylinders were considered by implementing a narrow Gaussian distribution of track radii. Details to the model and analysis procedure can be found elsewhere [26].

Raman spectra were obtained with a Horiba Jobin Yvon (HR800) micro-Raman spectrometer with a $20 \mathrm{~mW}$ HeNe-Laser as an excitation source $(\lambda=632.82 \mathrm{~nm})$. The flat polished specimens were measured in backscattering geometry, and the Raman signal was collected from a spot diameter of $\sim 2 \mu \mathrm{m}$. The measurement times varied from sample to sample and were optimized to obtain suitable intensity.

\section{RESULTS AND DISCUSSION}

\section{A. Radiation damage}

\section{Transmission electron microscopy}

Representative bright-field images of ion tracks in $\mathrm{Gd}_{2} \mathrm{Ti}_{2} \mathrm{O}_{7}$ and $\mathrm{La}_{2} \mathrm{Ti}_{2} \mathrm{O}_{7}$ are shown in Fig. 3. Diffraction contrast between the tracks and the surrounding matrix is evident. The amorphous tracks appear darker due to a density difference between the disordered track structure and the crystalline matrix. By evaluating the width of about 15 tracks (measuring the boundaries of the parallel track projections between the modified contrast and the unchanged 
matrix), mean track diameters, $d$, of $9.7 \pm 0.5 \mathrm{~nm}$ and $10.8 \pm 0.8 \mathrm{~nm}$ were deduced for $\mathrm{Gd}_{2} \mathrm{Ti}_{2} \mathrm{O}_{7}$ and $\mathrm{La}_{2} \mathrm{Ti}_{2} \mathrm{O}_{7}$, respectively. Similar track diameters are noted in HRTEM images, where the diameter for $\mathrm{Gd}_{2} \mathrm{Ti}_{2} \mathrm{O}_{7}$ is $9.1 \pm 0.6 \mathrm{~nm}$ and that for $\mathrm{La}_{2} \mathrm{Ti}_{2} \mathrm{O}_{7} 10.2 \pm 0.7 \mathrm{~nm}$ (table 1). The diameters extracted from the HRTEM images are in good agreement with the bright-field images; they both indicate that the average track diameter of $\mathrm{Gd}_{2} \mathrm{Ti}_{2} \mathrm{O}_{7}$ is smaller than that of the $\mathrm{La}_{2} \mathrm{Ti}_{2} \mathrm{O}_{7}$ by $\sim 1.2 \mathrm{~nm}$.

Fast Fourier Transformation (FFT) analysis of the HRTEM images was used to reveal the details of the local atomic structure of the region directly surrounding the track core. Observation of the disappearance of pyrochlore superstructure diffraction within the track shell region confirmed that $\mathrm{Gd}_{2} \mathrm{Ti}_{2} \mathrm{O}_{7}$ has a $\sim 1.5 \mathrm{~nm}$ defect-fluorite shell that surrounds the amorphous core track (Fig. 3, insets). The disordering to the defect-fluorite structure of $\mathrm{Gd}_{2} \mathrm{Ti}_{2} \mathrm{O}_{7}$ has been also noted in previous studies [7, 27-28]. In agreement to these previous studies, the $\operatorname{Gd}_{2} \mathrm{Ti}_{2} \mathrm{O}_{7}$ 's disordered crystalline phase of defect-fluorite structure noted in this study has the same crystallographic orientation as the surrounding pyrochlore matrix. The dark contrast at the boundary between the defect-fluorite and the pyrochlore structure seen in Fig 3 (b) is possibly due to strain from relative swelling caused by the irradiation within the different phases (i.e., amorphous, defect fluorite, and pyrochlore). The weaker contrast surrounding the defect-fluorite shell and extending to the pyrochlore matrix could be attributed to the defect-rich pyrochlore that surrounds the core, creating residual microstrain. The residual strain from local defects is also noted in HRTEM single ion track image for the $\mathrm{La}_{2} \mathrm{Ti}_{2} \mathrm{O}_{7}$. However, unlike $\mathrm{Gd}_{2} \mathrm{Ti}_{2} \mathrm{O}_{7}$, when $\mathrm{La}$ occupies the A-site, the track morphology shows a sharp transition between the matrix and the amorphous track core, which has been reported recently [29] and is in agreement to observations on the related compound $\mathrm{La}_{2} \mathrm{TiO}_{5}$ by Tracy el al. [30]. From previous molecular dynamics (MD) 
calculations, it has been suggested that the defect-fluorite structured tracks are a result of damage recovery, as well as epitaxial recrystallization at the interface of the molten track core and the surrounding crystalline matrix [12,31]. These calculations showed that the recrystallization process starts from the cooler, outer matrix and advances inward to the central molten core during the later phase of track formation. The observation that tracks in $\mathrm{La}_{2} \mathrm{Ti}_{2} \mathrm{O}_{7}$ are larger than those in $\mathrm{Gd}_{2} \mathrm{Ti}_{2} \mathrm{O}_{7}$ can be attributed to an insufficient stability of the disordered phase, preventing recrystallization in the compound's melted thermal spike region [30]. Because the cation-anion radius ratio of $\mathrm{La}_{2} \mathrm{Ti}_{2} \mathrm{O}_{7}$ is large $\left(\mathrm{r}_{\mathrm{A}} / \mathrm{r}_{\mathrm{B}}=1.94\right)$, the recrystallization into a defect fluorite phase is unfavorable. These results suggest that lanthanum titanates are more susceptible to radiation damage, i.e., the entire melted track volume of La-titanate remains amorphous during the quenching phase, because it cannot recrystallize to a disordered defect fluorite structure, as in the case of pyrochlore. The higher susceptibility to radiation of $\mathrm{La}_{2} \mathrm{Ti}_{2} \mathrm{O}_{7}$ as compared with $\mathrm{Gd}_{2} \mathrm{Ti}_{2} \mathrm{O}_{7}$ was also observed in another study [32], in which the compound was amorphized by irradiations with low-energy (keV-MeV) ions.

\section{Synchrotron X-ray diffraction}

A series of representative $X$-ray diffraction patterns of $\mathrm{La}_{2} \mathrm{Ti}_{2} \mathrm{O}_{7}$ and $\mathrm{Gd}_{2} \mathrm{Ti}_{2} \mathrm{O}_{7}$ samples irradiated with $2 \mathrm{GeV}$ Ta ions and fluences between $1 \times 10^{10}$ to $1 \times 10^{13}$ ions $/ \mathrm{cm}^{2}$ are presented in Fig. 4(a). For both compounds, the intensities of all sharp crystalline diffraction maxima are reduced with increasing fluence. Concurrently, the broad diffuse-scattering background increases, confirming the crystalline-to-amorphous transition. At the highest fluence of $1 \times 10^{13}$ ions $/ \mathrm{cm}^{2}$, both compounds are fully amorphized, as evidenced by the complete disappearance of the sharp diffraction peaks. For $\mathrm{Gd}_{2} \mathrm{Ti}_{2} \mathrm{O}_{7}$, the diffuse scattering of the amorphous phase becomes apparent at a fluence of $10^{12}$ ions $/ \mathrm{cm}^{2}$ around $2 \theta \approx 10^{\circ}, 12.4^{\circ}, 17^{\circ}$ and $20^{\circ}$; whereas for $\mathrm{La}_{2} \mathrm{Ti}_{2} \mathrm{O}_{7}$, peak 
broadening is noticed at a fluence of $5 \times 10^{11} \mathrm{ions} / \mathrm{cm}^{2}$ at $2 \theta \sim 6.5^{\circ}, 9.1^{\circ}$ and $13.5^{\circ}$. Yet, for both compounds, the peak intensities of the crystalline remnants decrease in the same systematic manner as the amorphization proceeds, and the peak widths significantly increase with fluence. For quantitative analysis, the contributions of the crystalline and amorphous phases were deduced by a deconvolution procedure with subsequent peak-fitting [1]. The evolution of the amorphous fraction as a function of fluence is shown in Fig 4(b). In the fluence regime where tracks are not yet overlapped, the amorphous fraction increases linearly for both compounds and finally saturate at higher fluences. Once again, we find that $\mathrm{La}_{2} \mathrm{Ti}_{2} \mathrm{O}_{7}$ is more susceptible to radiation damage with its data lying slightly above that of the $\mathrm{Gd}_{2} \mathrm{Ti}_{2} \mathrm{O}_{7}$. The evolution of the amorphous fraction is described by an exponential function based on a direct-impact model:

$$
f_{\mathrm{A}}(\Phi)=1-\mathrm{e}^{-(\sigma \Phi)}
$$

where $f_{\mathrm{A}}$ represents the amorphous fraction as a function of fluence $(\Phi)$, and $\sigma$ is the crosssectional area of the amorphous track produced by individual ions [33]. By fitting the XRD data to this exponential function, one can estimate the amorphization cross-section, $\sigma$. Assuming cylindrical track geometry, the track diameter, $d$, deduced from the cross section $\left(\sigma=\pi(d / 2)^{2}\right)$ is $6.2 \pm 0.7 \mathrm{~nm}$ for $\mathrm{Gd}_{2} \mathrm{Ti}_{2} \mathrm{O}_{7}$ and $7.2 \pm 0.9 \mathrm{~nm}$ for $\mathrm{La}_{2} \mathrm{Ti}_{2} \mathrm{O}_{7}$. These values are smaller than those directly measured from the TEM images. The discrepancy may be due to that data obtained from XRD results from the amorphous track core, whereas TEM contrast may be influenced by defect-rich regions outside of the amorphous volume [27,29]. Different analytical techniques reveal the properties of materials at different length scales. This has already been demonstrated by Lang et al., (2009) where they observed smaller track diameters obtained by XRD measurements as compared with other analytical techniques [27]. Here, Lang et al., also explained that the damage cross section is determined by the increasing amorphous contribution 
to the background in the XRD spectra without considering possible contributions from other types of radiation damage [27]. Additionally, due to the complex relation between peak intensities and the crystalline/amorphous phase distribution, the amorphous fractions presented from the XRD pattern should not be treated as absolute measurements of the volume of material amorphized by swift heavy ions, but rather as indicative of relative amorphous fractions in these similar materials [29,34]. Nevertheless, XRD allows a qualitative measurement that is appropriate for comparing relative radiation tolerance in $\mathrm{A}_{2} \mathrm{~B}_{2} \mathrm{O}_{7}$-type materials of different structures. Moreover, the general pattern of the current XRD result agrees well with the results of the TEM analysis.

\section{Raman spectroscopy}

The evolution of the observed Raman spectra for the $\mathrm{Gd}_{2} \mathrm{Ti}_{2} \mathrm{O}_{7}$ and $\mathrm{La}_{2} \mathrm{Ti}_{2} \mathrm{O}_{7}$ with increasing fluence at wavenumbers in the range $150-900 \mathrm{~cm}^{-1}$ is shown in Fig. 5. For $\mathrm{Gd}_{2} \mathrm{Ti}_{2} \mathrm{O}_{7}$, the most prominent Raman bands are found at $\sim 320 \mathrm{~cm}^{-1}\left[\mathrm{~T}_{2 \mathrm{~g}} \& \mathrm{E}_{\mathrm{g}}\right]$ and $\sim 515 \mathrm{~cm}^{-1}\left[\mathrm{~A}_{1 \mathrm{~g}}\right]$, which are assigned to the O-Gd-O bending mode and Gd-O stretching mode, respectively [35-37]. The intensity of these crystalline vibration modes decreases with increasing fluence. The broad band of the amorphous volume dominates the whole spectrum at the highest fluence $\left(1 \times 10^{13}\right.$ ions $/ \mathrm{cm}^{2}$ ), consistent with the results of the XRD analysis. The intensity decrease of the O-Gd-O bending mode is due to the transition from the ordered pyrochlore to the disordered, defectfluorite structure [38], as well as other modifications in the pyrochlore structure, such as straininduced distortion of bonds and the presence of simple point defects [39]. $\mathrm{La}_{2} \mathrm{Ti}_{2} \mathrm{O}_{7}$ has a more complex Raman spectrum due to the large number of Raman-active modes. Similar to $\mathrm{Gd}_{2} \mathrm{Ti}_{2} \mathrm{O}_{7}$, $\mathrm{La}_{2} \mathrm{Ti}_{2} \mathrm{O}_{7}$ shows a decreasing intensity of the crystalline vibration mode together with the growth of a large asymmetric background signal as the fluence increases. Of particular interest are the 
prominent Raman bands found at $\sim 153 \mathrm{~cm}^{-1}, 240 \mathrm{~cm}^{-1}$, and $343 \mathrm{~cm}^{-1}$, which are most likely La-

$\mathrm{O}$ bending modes [40]. Both $\mathrm{Gd}_{2} \mathrm{Ti}_{2} \mathrm{O}_{7}$ and $\mathrm{La}_{2} \mathrm{Ti}_{2} \mathrm{O}_{7}$ show a broad peak at around $800 \mathrm{~cm}^{-1}$ from the amorphous fraction, which suggests that the amorphous phases of the two materials are, indeed, quite similar i.e., their atomic arrangements at a full amorphous state are comparable. Although quantification of the Raman spectra is not possible due to the increase in the background with fluence, the evolution of the intensity profiles with increasing fluence is obvious in that the intensities of the crystalline vibrational modes decrease in a systematic manner. The loss of crystalline peaks in the Raman spectra is consistent with the results of the XRD analysis, further confirming the crystalline-to-amorphous transition of the two compounds with increasing fluence.

\section{B. Track formation and morphology}

All three analytical techniques, TEM, XRD, and Raman spectroscopy, confirm that the $\mathrm{La}_{2} \mathrm{Ti}_{2} \mathrm{O}_{7}$ is more susceptible to radiation damage. $\mathrm{La}_{2} \mathrm{Ti}_{2} \mathrm{O}_{7}$ shows aperiodicity at a lower fluence and exhibits a larger amorphous track diameter compared with $\mathrm{Gd}_{2} \mathrm{Ti}_{2} \mathrm{O}_{7}$. The crystalline-to-amorphous phase transition for the two compounds are related to the highly localized, extreme energy deposition conditions from swift heavy ions. As energy is transferred to electrons along the ion path, the local atomic structure is driven far from equilibrium, eventually resulting in disorder. The difference in the susceptibility to radiation damage and the process of recovery in these compounds can be understood in terms of energy landscapes and the process of damage recovery.

Depending on the physical variables of temperature and pressure, irradiated pyrochlore materials can remain as pyrochlore $(F d \overline{3} m)$, be quenched to the amorphous state, or recover to a 
disordered defect fluorite structure $(F m \overline{3} m$, ). The recovery of the initial structure within a melted region is kinetically limited by the rapid quench time of ion tracks, which means that access of a material to stable disordered phases, like defect-fluorite phase, is advantageous in terms of radiation tolerance, as their formation kinetics can be sufficiently fast to allow for recrystallization from the in-track melt prior to the loss of thermal energy and "freezing" of the current atomic arrangement. Ion irradiation-induced order-disorder transitions have been observed in pyrochlores, such as in the series of $\mathrm{Gd}_{2}\left(\mathrm{Zr}_{\mathrm{x}} \mathrm{Ti}_{1-\mathrm{x}}\right)_{2} \mathrm{O}_{7}[13,16]$. However, the thermodynamic instability of pyrochlores with large $\mathrm{r}_{\mathrm{A}} / \mathrm{r}_{\mathrm{B}}$ ratios means that the defect fluorite phase for Ti-rich pyrochlores cannot easily persist at a sufficiently high damage-level [41]. This is in contrast to the $\mathrm{Zr}$-rich pyrochlores where the defect-fluorite structure remains stable even at a damage level of $\sim 100 \mathrm{dpa}$ [42]. The different radiation response of Ti and Zr-rich pyrochlores is, in part, understood to be the result of the relative sizes of the ionic radii of A- and B-site cations. The susceptibility of radiation decreases if the A- and B-site cations have similar ionic radii, which in turns, increases the ability to accommodate structural disorder by lowering the formation energy of the antisite defect [41]. The disordering of pyrochlore materials to the defect-fluorite structure is equivalent to the formation of antisite defects (an A-site cation occupying the B-site and vice versa) on the cation sublattice and anti-Frenkel pairs (oxygen vacancies and interstitials) on the anion sublattice. In the case of $\mathrm{Gd}_{2} \mathrm{Ti}_{2} \mathrm{O}_{7}$, for which the cation radius ratio is rather high $\left(\mathrm{r}_{\mathrm{A}} / \mathrm{r}_{\mathrm{B}}=1.74\right)$, the defect-fluorite phase is metastable, and the track consists of a mostly amorphous region at higher fluences, with only a thin shell of defect fluorite structure surrounding the core. When the cation radius ratio is greater than 1.78 , as is the case for perovskite $\mathrm{La}_{2} \mathrm{Ti}_{2} \mathrm{O}_{7}$, the order-disorder transition does not occur upon irradiation, and the compound either remains in its original structure, $P 2{ }_{1}$, or becomes amorphous. In the case of 
$\mathrm{A}_{2} \mathrm{TiO}_{5}$, it has been shown that materials that do not exhibit the fluorite structure as an equilibrium phase can still form structure defect-fluorite phase as an ion track shell under swift heavy ion irradiation as long as the $r_{A} / r_{B}$ is low enough [30]. Similar transformations to a disordered fluorite structure have been shown for swift heavy ion irradiated monoclinic $\mathrm{A}_{4} \mathrm{Zr}_{3} \mathrm{O}_{12}$ materials [43]. This indicates that the defect fluorite structure is a phase that exhibits uniquely favorable kinetics of formation from an in-track melt comprised of oxygen and both trivalent and tetravalent cations in stoichiometric ratios similar to that of the pyrochlore compounds. Materials for which the defect fluorite structure is stable (or metastable) are generally less susceptible to swift heavy ion amorphization, because formation of this fluorite phase provides a rapid transformation pathway to a crystalline atomic arrangement. Overall, with increasing ion fluence, radiation damage accumulation generally causes these complex oxides to simply lose their periodicity, and become amorphous, unless such a disordering phase pathway is energetically accessible, based on a material's cation ionic radius ratio. In the absence of an order-disorder transition, due to its relatively large A-site cation, $\mathrm{La}_{2} \mathrm{Ti}_{2} \mathrm{O}_{7}$ becomes amorphous at lower fluences as compared with $\mathrm{Gd}_{2} \mathrm{Ti}_{2} \mathrm{O}_{7}$, which explains the larger tracks in $\mathrm{La}_{2} \mathrm{Ti}_{2} \mathrm{O}_{7}$.

\section{Annealing behavior}

\section{Synchrotron X-ray diffraction}

The bulk annealing behavior of the two compounds was characterized using XRD. Representative XRD patterns, as a function of increasing temperature, are shown in Fig 6(a). Both compounds recover their original structures by the highest temperature achieved $\left(850^{\circ} \mathrm{C}\right)$. $\mathrm{Gd}_{2} \mathrm{Ti}_{2} \mathrm{O}_{7}$ does not transform into a defect fluorite structure during the heating process, in contrast to the behavior of irradiated $\mathrm{Gd}_{2} \mathrm{Zr}_{2} \mathrm{O}_{7}$, which readily disorders into a defect fluorite structure [44]. The absence of a defect-fluorite polymorph for this pure titanate pyrochlore has 
been explained by Sickafus et al. [45], who suggested that no thermal cation disordering will occur when the formation enthalpy of antisite defects is high enough. Thus, the defect fluorite structure is not thermodynamically favored [45]. The XRD patterns were quantitatively analyzed by deconvolution of diffraction peaks and diffuse scattering from the amorphous phase as a function of irradiation fluence, the same procedure used to analyze radiation-induced amorphization, to quantify the recovery of the crystalline phases. The result reveals a sigmoidal trend of increasing crystalline fraction with increasing annealing temperature for both compounds, where both samples remain amorphous until they reach a specific point after which recrystallization is almost instantaneous (Fig. 6(b)). The sigmoidal annealing trend can be attributed to the kinetics and thermodynamics of nucleation of a crystalline volume, where recovery is inhibited until a certain temperature. This recovery temperature is associated with the activation energy necessary for displacement of atoms from the materials' initial positions in the amorphous structure to positions that are characteristic of the recovered crystalline phase. Assuming that the two materials have a similar starting point in terms of their atomic arrangements in the amorphous phase (an assumption that is appropriate based on the Raman results, which exhibit similar broad peaks at around $800 \mathrm{~cm}^{-1}$ ), the difference in the two materials' recovery temperatures could be due to the fact that the atomic arrangements needed to form one phase are different from those needed to form the other. A very similar sigmoidal trend has also been observed for $\mathrm{Cm}$-doped pyrochlores $\left(\mathrm{Gd}_{2} \mathrm{Ti}_{2} \mathrm{O}_{7}\right.$ and $\left.\mathrm{CaZrTi}_{2} \mathrm{O}_{7}\right)$ damaged by recoil-nuclei and alpha particles [46]. Because the self-damage for $\mathrm{Cm}$-doped pyrochlore and the radiationinduced transformation from swift heavy ions is comparable, our results suggest that ion irradiation can be used to simulate self-damage created by alpha-decay events. 
The point of inflection in the figure 6(b) is extrapolated to the bulk recrystallization temperature $\left(\mathrm{T}_{\mathrm{r}}\right)$ - the temperature at which $50 \%$ of material achieves crystallinity. $\mathrm{Gd}_{2} \mathrm{Ti}_{2} \mathrm{O}_{7}$ has a $\mathrm{T}_{\mathrm{r}}$ of $\sim 785^{\circ} \mathrm{C}$ and $\mathrm{La}_{2} \mathrm{Ti}_{2} \mathrm{O}_{7}$ of $\sim 690^{\circ} \mathrm{C}$. The lower $\mathrm{T}_{\mathrm{r}}$ of $\mathrm{La}_{2} \mathrm{Ti}_{2} \mathrm{O}_{7}$ as compared with $\mathrm{Gd}_{2} \mathrm{Ti}_{2} \mathrm{O}_{7}$ may be counter intuitive, because $\mathrm{La}_{2} \mathrm{Ti}_{2} \mathrm{O}_{7}$ is described as being more susceptible to radiation damage. Previous studies suggest that for pyrochlores, the composition that accumulates the most damage from irradiation will have a higher activation energy for recrystallization since more energy and time are needed to remove the radiation-induced defects $[47,48]$. However, when two different crystalline structures are involved in the radiation-induced transformation (pyrochlore and layered-perovskite), the recrystallization process depends on the energy difference between the amorphous state and possible crystalline structures, along with the differing kinetics of the atomic rearrangements necessary to recover these different structures. Based on topologic considerations [48], $\mathrm{La}_{2} \mathrm{Ti}_{2} \mathrm{O}_{7}$ has a higher degree of structural freedom, i.e., fewer structural constraints, and hence, a lower degree of connectivity. Unlike $\mathrm{La}_{2} \mathrm{Ti}_{2} \mathrm{O}_{7}$, $\mathrm{Gd}_{2} \mathrm{Ti}_{2} \mathrm{O}_{7}$ has an anion lattice that has two well-defined cation sites, $16 c$ and $16 d$, and three distinct oxygen positions: $48 f, 8 a$ and the vacant $8 b$ position $[5,6,11,49]$. The only internal coordinate that is variable in this pyrochlore structure is the oxygen position at $48 f$. These greater topologic constraints on the pyrochlore structure means that the compound has a higher atomic connectivity that cannot easily incorporate distortion from its ideal structure. The energetic barrier to rearrangement is therefore higher and recrystallization of $\mathrm{Gd}_{2} \mathrm{Ti}_{2} \mathrm{O}_{7}$ occurs at a higher temperature as compared with $\mathrm{La}_{2} \mathrm{Ti}_{2} \mathrm{O}_{7}$ (Fig.8). Formation enthalpies of the two compounds could be another supportive argument. $\mathrm{La}_{2} \mathrm{Ti}_{2} \mathrm{O}_{7}$ has a formation enthalpy of $\Delta \mathrm{H}_{\mathrm{f}}{ }^{\circ}=-3855.5 \pm$ $3.5 \mathrm{~kJ} / \mathrm{mol}$, which is $33 \mathrm{~kJ} / \mathrm{mol}$ lower than that of $\mathrm{Gd}_{2} \mathrm{Ti}_{2} \mathrm{O}_{7}$, which could possibly suggest that $\mathrm{La}_{2} \mathrm{Ti}_{2} \mathrm{O}_{7}$ has a higher stability when crystalline [50]. 


\section{Small angle X-ray scattering}

Small angle X-ray scattering (SAXS) was performed on samples irradiated at $5 \times 10^{11}$ ions $/ \mathrm{cm}^{2}$. At room temperature, the track diameters of the two compounds deduced from SAXS are $11.3 \pm 0.2 \mathrm{~nm}$ and $10.6 \pm 0.2 \mathrm{~nm}$ for $\mathrm{Gd}_{2} \mathrm{Ti}_{2} \mathrm{O}_{7}$ and $\mathrm{La}_{2} \mathrm{Ti}_{2} \mathrm{O}_{7}$, respectively. As stated above, each analytical technique can give contrasting track diameters for the same materials due to the different length-scales probed. The discrepancy in the track diameters from SAXS compared with those from TEM exists because SAXS probes the shape and size of the features that involve electronic density differential; whereas, TEM probes the long range order of a material at a certain penetration depth. More specifically, SAXS measures the entire damaged volume of the track whereas TEM provides a measure of the aperiodic domain size in a small, low penetration depth portion of the track that is preserved after sample thinning, which could be responsible for the difference in the track sizes. The analysis further illustrates complimentary, yet dissimilar results for annealing behavior as compared with XRD analysis (Fig. 7). SAXS shows a continual recrystallization of the two compounds represented by the decrease in the amorphous track radii, unlike XRD that gives sigmoidal profiles. The dissimilar trends can be attributed to the difference in bulk recrystallization (as measured in the XRD experiments on fully amorphous material) and isolated track annealing (as measured in the SAXS experiments on partiallyamorphous tracks embedded in a fully crystalline, unirradiated matrix). In the former case, recrystallization requires both the local formation of small crystalline zones within an amorphous matrix (nucleation) and the epitaxial expansion of the resulting crystallite as it incorporates adjacent amorphous material into its structure (growth). In contrast, the shrinkage of isolated ion tracks requires no nucleation, as an interface between the amorphous track and the crystalline matrix exists prior to the application of heat. Thus, the recovery of isolated track damage is 
kinetically limited and shows a more continuous track annealing process (based on the SAXS data), whereas recovery of bulk damage is nucleation limited, such that the recrystallization process is almost spontaneous once the threshold for nucleation is reached i.e., size of the nucleus is big enough. We observe that, for both materials tested, the onset temperature for bulk recrystallization, $\mathrm{T}_{\mathrm{r}}$, is higher than that for track annealing, $\mathrm{T}_{\mathrm{a}}$. This observation is in agreement with previously documented studies [51,52]. In fact, track annealing, indicated by a measured decrease in the track radii determined by SAXS analysis, has begun at the lowest temperature, for which SAXS data was collected. The delay in $\mathrm{T}_{\mathrm{r}}$ as compared with the $\mathrm{T}_{\mathrm{a}}$ can be attributed to the fact that the energy necessary for the nucleation of a crystallite of a size (and therefore stability) suitable for subsequent growth, rather than dissolution, is large compared to the energy needed for the epitaxial growth of either crystalline phase at a crystalline-amorphous interface.

Comparison of the annealing of isolated tracks in the two materials tested shows that, in contrast to the results for recrystallization of an amorphous phase, the annealing rate does not differ significantly between the $\mathrm{Gd}_{2} \mathrm{Ti}_{2} \mathrm{O}_{7}$ and $\mathrm{La}_{2} \mathrm{Ti}_{2} \mathrm{O}_{7}$. As discussed previously, the differing bulk recrystallization behavior of these materials is a result of differences in the kinetics of the nucleation of an ordered volume that arise from distinct topological constrains on the formation of the pyrochlore and layered-perovskite structures. In the case of isolated track annealing, as was studied by SAXS characterization, to no such nucleation is required. Therefore, these topological effects do not control this recovery, which instead depends primarily on the displacement of atoms in the amorphous in-track volume to positions consistent with the epitaxial growth of the crystalline phase. In other words, the amorphous-crystalline interface moves towards the ion track centerline as the tracks shrink in the radial direction. The Raman spectroscopy results reported here suggest that the short-range structure of the amorphous phases 
in both $\mathrm{Gd}_{2} \mathrm{Ti}_{2} \mathrm{O}_{7}$ and $\mathrm{La}_{2} \mathrm{Ti}_{2} \mathrm{O}_{7}$ are similar, so the energetics and kinetics of the epitaxial recrystallization process are likely similar for ion tracks in the two materials.

Residual defects (track radii) are still observed for both samples from SAXS even after they had been annealed for 20 minutes at $940^{\circ} \mathrm{C}$. The remnants of defects from SAXS could be due to increased stability of tracks with very small diameters, where surface energy effects can dominate the energy reduction that accompanies crystallization. The remnants are not observed by XRD, because XRD analysis provides information on the long-range, atomic-scale periodicity and is not sensitive to such local structural damage. Overall, the two processes (bulk sample recrystallization versus isolated track damage recovery) are governed by different mechanisms; therefore, the track sizes as measured by XRD and SAXS should not be directly compared. However, XRD and SAXS provide complementary information on mechanisms for the recovery of the two radiation-damaged structures.

\section{CONCLUSION}

The response of a cubic pyrochlore, $\mathrm{Gd}_{2} \mathrm{Ti}_{2} \mathrm{O}_{7}$, and a monoclinic-layered perovskite, $\mathrm{La}_{2} \mathrm{Ti}_{2} \mathrm{O}_{7}$, to swift heavy ion irradiation and subsequent thermal annealing has been systematically investigated using TEM, XRD, Raman spectroscopy, and SAXS. Analyses confirm that $\mathrm{La}_{2} \mathrm{Ti}_{2} \mathrm{O}_{7}$ has a higher susceptibility to radiation damage, and thus amorphizes more rapidly with increasing ion fluence, as compared with $\mathrm{Gd}_{2} \mathrm{Ti}_{2} \mathrm{O}_{7}$. This increased susceptibility to radiation damage is evident in larger amorphous ion tracks in $\mathrm{La}_{2} \mathrm{Ti}_{2} \mathrm{O}_{7}$ as compared with $\mathrm{Gd}_{2} \mathrm{Ti}_{2} \mathrm{O}_{7}$, resulting primarily from a decreased extent of recrystallization of melted material within the tracks to a disordered phase during quenching. While $\mathrm{La}_{2} \mathrm{Ti}_{2} \mathrm{O}_{7}$ showed no evidence of such dynamic recovery, $\mathrm{Gd}_{2} \mathrm{Ti}_{2} \mathrm{O}_{7}$ displayed partial recrystallization at the periphery of the track 
into a defect-fluorite structure. The difference in the radiation responses of the two compounds was attributed to distinct energetics of the order-disorder transition and the energy landscapes of available structures during ion track formation.

When annealed, fully amorphized $\mathrm{La}_{2} \mathrm{Ti}_{2} \mathrm{O}_{7}$ recrystallized at a lower temperature as compared with amorphous $\mathrm{Gd}_{2} \mathrm{Ti}_{2} \mathrm{O}_{7}$. The annealing experiments suggests that in damage recovery, topology plays an important role in determining the rates and temperature at which the two compounds anneal. With lower structural constraints, $\mathrm{La}_{2} \mathrm{Ti}_{2} \mathrm{O}_{7}$ recrystallizes into its original structure more easily, as its activation energy for structural recovery is lower. However, the same topology dependence was not observed in the recovery of isolated ion tracks embedded in a crystalline matrix. This is because the recrystallization of a fully amorphous material is based on a nucleation and growth process, wherein topological effects primarily influence the nucleation stage. In contrast, recovery of isolated tracks depends solely on the epitaxial growth of a preexisting crystalline volume. In this way, the physical processes controlling the ability of a complex oxide to recover from swift heavy ion irradiation damage, and their compositional and structural dependences, were shown to vary with the spatial distribution of radiation damage.

In situ irradiation and annealing of the two compounds provides a fundamental understanding of the roles of kinetics and thermodynamics in radiation damage accumulation and recrystallization behavior. $\mathrm{La}_{2} \mathrm{Ti}_{2} \mathrm{O}_{7}$, with a lower $\mathrm{T}_{\mathrm{r}}$, may anneal more efficiently than $\mathrm{Gd}_{2} \mathrm{Ti}_{2} \mathrm{O}_{7}$ when being simultaneously irradiated and heated. If kinetics dominate over the thermodynamic constraints associated with the stability of disordered phases, and damage recovery in $\mathrm{La}_{2} \mathrm{Ti}_{2} \mathrm{O}_{7}$ dominates the higher radiation damage tolerance of $\mathrm{Gd}_{2} \mathrm{Ti}_{2} \mathrm{O}_{7}$, a temperature range may be found where $\mathrm{La}_{2} \mathrm{Ti}_{2} \mathrm{O}_{7}$ is more stable than $\mathrm{Gd}_{2} \mathrm{Ti}_{2} \mathrm{O}_{7}$ under swift heavy ion irradiation. These results show that, in assessing the radiation tolerance of complex oxides in, for example, nuclear 
wasteform applications, the thermal environment and associated material recovery kinetics must be considered in addition to ambient temperature radiation damage tolerance.

\section{Acknowledgements}

This material is based upon work supported by the U.S. Department of Energy Office of Science,

Office of Basic Energy Sciences Energy Frontier Research Center program, Materials Science of Actinides, under Award Number DE-SC0001089. SGYP acknowledges a graduate fellowship from Stanford University. The swift heavy ion irradiations were completed at the GSI Hemholtz Center for Heavy ion Research. The use of CHESS beam is supported by NSF \& NIH/NIGMS via NSF award DMR-0225180. The Electron Micro-beam Analysis Laboratory at the University of Michigan is supported by NSF Grants DMR-987177 and DMR-0723032. Part of the research was performed at the SAXS/WAXS beamline at the Australian Synchrotron. PK acknowledges the Australian Research Council for financial support.

\section{REFERENCES}

[1] R.C. Ewing, W.J Weber, F.W.J. Clinard, Radiation effects in nuclear waste forms for highlevel radioactive waste, Prog. Nucl. Energy. 29 (1995) 63-127.

[2] P.J. Wilde, C.R.A. Catlow, Defects and diffusion in pyrochlore structured oxides, Solid State Ion. 112 (1998) 173-183.

[3] G.R. Lumpkin, Alpha-decay damage and aqueous durability of actinide host phases in natural systems, J. Nucl. Mater. 289 (2001) 136-166.

[4] P.K. Schelling, S.R. Phillpot, R.W. Grimes, Optimum pyrochlore compositions for low thermal conductivity, Phil. Mag. Lett. 84 (2004) 127-137. 
[5] A. Subramanian, G. Aravamudan, G.V. Subba Rao, Oxide Pyrochlores - a Review, Prog. Solid State Chem. 15 (1983) 55-143.

[6] B.C. Chakoumakos, Systematics of the Pyrochlore Structure Type, Ideal $A_{2} B_{2} X_{6} Y$, J. Solid State Chem. 53 (1984) 120-129.

[7] M. Lang, F.X. Zhang, J.M Zhang, J.W. Wang, J. Lian, W. J Weber, B. Schuster, C.

Trautmann, R. Neumann, R.C. Ewing, Review of $\mathrm{A}_{2} \mathrm{~B}_{2} \mathrm{O}_{7}$ pyrochlore response to irradiation and pressure, Nucl. Instrum. Meth. B. 268 (2010) 2951-2959.

[8] F. X. Zhang et al., Structural change of layered perovskite $\mathrm{La}_{2} \mathrm{Ti}_{2} \mathrm{O}_{7}$ at high pressures, J. Solid State Chem. 180 (2007) 571-576.

[9] J. Lian, R. C. Ewing, L. M. Wang, Ion-beam irradiation of $\mathrm{Gd}_{2} \mathrm{Sn}_{2} \mathrm{O}_{7}$ and $\mathrm{Gd}_{2} \mathrm{Hf}_{2} \mathrm{O}_{7}$ pyrochlore: Bond-type effect, J. Mater. Res 19 (2004) 1575-1580.

[10] M. Lang, F.X. Zhang, J.M. Zhang, J.W. Wang, B. Schuster, C. Trautmann, R. Neumann, U. Becker, R.C. Ewing, Nanoscale manipulation of the properties of solids at high pressure with relativistic heavy ions, Nature Mat. 8 (2009) 793-797.

[11] G. Sattonay et al., Effect of composition on the behavior of pyrochlores irradiated with swift heavy ions, Nucl. Instrum. Meth. B. 272 (2012) 261-265.

[12] J.M. Zhang, M. Lang, R.C. Ewing, Nanoscale phase-transitions under extreme conditions within an ion track, Mat. Res. Soc. 25 (2010) 1344-1351.

[13] S.W. Wang et al., Radiation stability of gadolinium zirconate: a waste formed for plutonium disposition, J. Mater Res. 14 (1999) 4470-4473.

[14] B.D. Bregg et al,. Heavy ion irradiation effects in pyrochlores, Ceram Trans. 107 (2000) $553-557$. 
[15] R.C. Ewing, L.M Wang, Amorphization of zirconolite: Alpha-decay event damage versus krypton ion irradiation, Nucl. Instrum. Meth. B. 65 (1992) 319-323.

[16] S.X. Wang, L.M. Wang, R.C. Ewing, G.S. Was, G.R. Lumpkin, Ion irradiation-induced phase transformation of pyrochlore and zirconolite, Nucl. Instrum. Meth. B. 148 (1999) 704-709. [17] Y. Zhang, V. Shuttanandan, R. Devanathan, S. Thevuthasan, D.E, McCready, J. Young, G. Balakrishnan, D.M. Paul, W.J. Weber, Damage accumulation and amorphization in samarium titanate pyrochlore, Nucl. Instrum. Meth. B. 218 (2004) 89-94.

[18] S. Nanamatsu, M. Kimura, Ferroelectric properties of $\mathrm{Ca}_{2} \mathrm{Nb}_{2} \mathrm{O}_{7}$ single crystal, J. Phys. Soc. Jpn. 36 (1974) 1495.

[19] S. Nanamatsu, M. Kimura, K. Doi, S. Matsushita, N. Yamada, A new ferroelectric: $\mathrm{La}_{2} \mathrm{Ti}_{2} \mathrm{O}_{7}$, Ferroelectrics. 8 (1974) 511-513.

[20] J.K. Yamamoto, D. A. McHenry, A.S. Bhalla, Strontium barium niobate single-crystal fibers: Optical and electro-optic properties, J. Appl. Phys. 70 (1991) 3215-3222.

[21] F.X. Zhang, J.W. Wang, J. Lian, M. Lang, U. Becker, R.C. Ewing, Phase stability and pressure dependence of defect formation in $\mathrm{Gd}_{2} \mathrm{Ti}_{2} \mathrm{O}_{7}$ and $\mathrm{Gd}_{2} \mathrm{Zr}_{2} \mathrm{O}_{7}$ pyrochlores, Phys.Rev.Lett. 100 (2008) 045503.

[22] J.F. Ziegler, M.D. Ziegler, J.P. Biersack, SRIM - The stopping and range of ions in matter, Nucl. Instrum. Meth. B. 268 (2010) 1818-1823.

[23] A.P. Hammersley, FIT2D, ESRF, Grenoble, France; 1998.

[24] J. Rodriguez-Carvaja, FULLPROF2K, France; 2001.

[25] M. Lang, F.X. Zhang, J. Lian, C. Trautmann, Z.W. Wang, R.C. Ewing, Structural modifications of $\mathrm{Gd}_{2} \mathrm{Zr}_{2-\mathrm{x}} \mathrm{Ti}_{\mathrm{x}} \mathrm{O}_{7}$ pyrochlore induced by swift heavy ions: Disordering and amorphization, J. Mat. Res. 24 (2009) 1322-1334. 
[26] B. Afra, M. Lang, M. D. Rodriguez, J. Zhang, R. Giulian, N. Kirby, R. C. Ewing, C. Trautmann, M. Toulemonde, and P. Kluth, Annealing kinetics of latent particle tracks in Durango apatite, Phys. Rev. B. 83 (2011) 064116.

[27] M. Lang, J. Lian, J.M. Zhang, F.X. Zhang, W.J. Weber, C. Trautmann, R.C. Ewing, Singleion tracks in $\mathrm{Gd}_{2} \mathrm{Zr}_{2-\mathrm{x}} \mathrm{Ti}_{\mathrm{x}} \mathrm{O}_{7}$ pyrochlores irradiated with swift heavy ions, Phys. Rev. B. 79 (2009) 224105.

[28] G, Sattonnay, C. Grygiel, I. Monnet, C. Legros, M. Herbst-Ghysel, L. Thome, Phenomenological model for the formation of heterogeneous tracks in pyrochlores irradiated with swift heavy ions, Acta Mater. 60 (2010) 22-34.

[29] S.G.Y. Park, M. Lang, C.L. Tracy, J.M. Zhang, F.X. Zhang, C. Trautmann, P. Kludth, M. Rodriguez, R.C. Ewing, Swift heavy ion irradiation-induced amorphization of $\mathrm{La}_{2} \mathrm{Ti}_{2} \mathrm{O}_{7}, \mathrm{Nucl}_{\text {. }}$ Instrum. Meth. B. 326 (2014) 145-149.

[30] C.L. Tracy, M. Lang, J.M. Zhang, F.X. Zhang, Z.W. Wang, R.C. Ewing, Structural response of $\mathrm{A}_{2} \mathrm{TiO}_{5}(\mathrm{~A}=\mathrm{La}, \mathrm{Nd}, \mathrm{Sm}, \mathrm{Gd})$ to swift heavy ion irradiation, Acta Mater. 60 (2012) 44774486.

[31] J.W. Zhang, M. Lang, R.C. Ewing, U. Becker, Multi-scale simulation of structural heterogeneity of swift-heavy ion tracks in complex oxides, J. Phys. Condens. Matter 25 (2012) 135001.

[32] J. Lian, F.X. Zhang, M.R. Peters, L.M. Wang, R.C. Ewing, Ion beam irradiation of lanthanum and thorium-doped yttrium titanates, J. Nucl Mat. 362 (2007) 438-444.

[33] W.J. Weber, Models and mechanisms of irradiation-induced amorphization in ceramics, Nucl. Instr. Meth. B 166-167 (2000) 98-106. 
[34] W.J. Weber, N.J. Hess, G.D. Maupin, Amorphization in $\mathrm{Gd}_{2} \mathrm{Ti}_{2} \mathrm{O}_{7}$ and $\mathrm{CaZrTi}_{2} \mathrm{O}_{7}$ Irradiated with $3 \mathrm{MeV}$ Argon Ions, Nucl. Instr. Meth. B 65 (1992) 102-106.

[35] M. Oueslati, M. Balkanski, P.K. Moon, H.L. Tuller, Raman Spectroscopy and Structural Disorder in $\mathrm{Gd}_{2} \mathrm{Zr}_{2} \mathrm{O}_{7}$, Solid State Ionic. 139 (1989) 199-206.

[36] M. Maczka et al., Temperature-dependent Raman scattering studies of the geometrically frustrated pyrochlores $\mathrm{Dy}_{2} \mathrm{Ti}_{2} \mathrm{O}_{7}, \mathrm{Gd}_{2} \mathrm{Ti}_{2} \mathrm{O}_{7}$ and $\mathrm{Er}_{2} \mathrm{Ti}_{2} \mathrm{O}_{7}$, J. Raman Spec. 39 (2008) 537-544. [37] M. Maczka et al., Temperature-dependent studies of the geometrically frustrated pyrochlores $\mathrm{Ho}_{2} \mathrm{Ti}_{2} \mathrm{O}_{7}$ and $\mathrm{Dy}_{2} \mathrm{Ti}_{2} \mathrm{O}_{7}$, Phys. Rev. B. 79 (2009) 214437.

[38] D. Michel, M. Perez, Y. Jorba, R. Collongues, Study by Raman spectroscopy of order-disorder phenomena occurring in some binary oxides with fluorite-related structures, J. Raman Spec. 5 (1976) 163-180.

[39] W.J. Weber, N.J. Hess, Ion beam modification of $\mathrm{Gd}_{2} \mathrm{Ti}_{2} \mathrm{O}_{7}$, Nucl Instrum Methods in Phys Res Sect B. 80/81 (1993) 1245-1248.

[40] Z. Shao et al, Structural Characterization and Photoluminescent Properties of ( $\mathrm{La}_{1-}$ $\left.{ }_{x} \mathrm{Sm}_{\mathrm{x}}\right)_{2} \mathrm{Ti}_{2} \mathrm{O}_{7}$ Solid Solutions Synthesized by a Sol-Gel Route, Eur. J. Inorg. Chem. 24 (2011) 3569-3576.

[41] J. Lian et al., The order-disorder transition in ion-irradiated pyrochlore, Acta Mater. 51 (2003) 1493-1502.

[42] J. Lian et al., Ion-irradiation-induced amorphization of $\mathrm{La}_{2} \mathrm{Zr}_{2} \mathrm{O}_{7}$ pyrochlore, Phys. Rev. B. 66 (2002) 054108.

[43] M. Tang et al., Swift heavy ion irradiation-induced microstructure modification of two delta-phase oxides: $\mathrm{Sc}_{4} \mathrm{Zr}_{3} \mathrm{O}_{12}$ and $\mathrm{Lu}_{4} \mathrm{Zr}_{3} \mathrm{O}_{12}$, Nucl. Instrum. Meth. B in Phys. Res. B, 268. (2010) 3243-3247. 
[44] C. Jiang, C.R. Stanek, K.E. Sickafus, B.P. Uberuaga, First-principles prediction of disordering tendencies in pyrochlore oxides, Phys. Rev. B 79, (2009) 104203.

[45] K.E. Sickafus et al., Radiation tolerance of complex oxides, Science. 289 (2000) 748-754.

[46] W.J. Weber, J.W. Wald, H.J. Matzke, Effects of self-radiation damage in Cm-doped $\mathrm{Gd}_{2} \mathrm{Ti}_{2} \mathrm{O}_{7}$ and $\mathrm{CaZrTi}_{2} \mathrm{O}_{7}$, J. Nucl. Mat. 138. (1986) 196-209.

[47] J. Lian et al., Radiation-induced amorphization of rare-earth titanate pyrochlores, Phys .Rev. B. 68 (2003) 134107.

[48] L.W. Hobbs, Topological approaches to the structure of crystalline and amorphous atom assemblies, in: J. Novoa, D. Braga, L. Addadi (Eds) Engineering of Crystalline Materials Properties, Netherlands, 2008, pp. 193-231.

[49] R.C. Ewing, Safe management of actinides in the nuclear fuel cycle: Role of mineralogy, Comptes Rendus Geoscience. 343. (2011) 219-229.

[50] K.B. Helean et al., Formation enthalpies of rare earth titanate pyrochlores, J. Sol. State. Chem. 177. (2004) 1858-1866.

[51] I. Jencic, E.P Hollar,I.M. Robertson, Crystallization of isolated amorphous zones in semiconductors, Philos. Mag., 83 (2003) 2557 - 2571.

[52] C.W. White, C. J. McHargue, P.S. Silad, L.A. Boatner, G.C. Farlow, Ion implantation and annealing of crystalline oxides, Mater. Sci. Reports. 4 (1989) 41.

\section{Figure caption}

FIG 1. Unit cell of (a) $\mathrm{Gd}_{2} \mathrm{Ti}_{2} \mathrm{O}_{7}(F d \overline{3} m)$ and (b) $\mathrm{La}_{2} \mathrm{Ti}_{2} \mathrm{O}_{7}\left(P 2_{1}\right)$ 
FIG 2. Electronic energy loss of $2.0 \mathrm{GeV}{ }^{181} \mathrm{Ta}$ ions in $\mathrm{Gd}_{2} \mathrm{Ti}_{2} \mathrm{O}_{7}$ and $\mathrm{La}_{2} \mathrm{Ti}_{2} \mathrm{O}_{7}$ as a function of penetration depth, as calculated using SRM 2008. For both compounds, the ion range is larger than the sample thickness. The energy loss within the sample thickness varies less than $10 \%$.

FIG 3. Bright-field and high resolution TEM images of single ion tracks in $(a, b) \operatorname{Gd}_{2} \mathrm{Ti}_{2} \mathrm{O}_{7}$ and (c,d) $\mathrm{Gd}_{2} \mathrm{Ti}_{2} \mathrm{O}_{7}$ irradiated with $2.0 \mathrm{GeV}{ }^{181} \mathrm{Ta}$ ions. (a) and (c) show track projections along the ion trajectoriesand (b) and (d) present the cross section of an individual track (d) $\mathrm{La}_{2} \mathrm{Ti}_{2} \mathrm{O}_{7}$. The small insets next to (b) and (c) present FFT analyses of the respective structures of the indicated frames. $\mathrm{Gd}_{2} \mathrm{Ti}_{2} \mathrm{O}_{7}$ has a defect fluorite shell surrounding the central core, whereas $\mathrm{La}_{2} \mathrm{Ti}_{2} \mathrm{O}_{7}$ has a direct crystalline-to-amorphous transition.

FIG 4. (a) Series of XRD patterns of $\mathrm{Gd}_{2} \mathrm{Ti}_{2} \mathrm{O}_{7}$ and $\mathrm{La}_{2} \mathrm{Ti}_{2} \mathrm{O}_{7}$ irradiated with $2 \mathrm{GeV}{ }^{181} \mathrm{Ta}$ ion at a fluence from $1 \times 10^{11}$ ions $/ \mathrm{cm}^{2}$ to $1 \times 10^{13}$ ions $/ \mathrm{cm}^{2}$. Amorphization occurs as a function of fluence, evident by the decrease in intensity of the diffraction peaks. (b) Amorphous fraction deduced from quantitative analysis of XRD patterns as a function of fluence. The curve is the best fit of the equation (in the box) and the error bars indicate the uncertainty from the fitting procedure.

FIG 5. Raman spectra of $\mathrm{Gd}_{2} \mathrm{Ti}_{2} \mathrm{O}_{7}$ and $\mathrm{La}_{2} \mathrm{Ti}_{2} \mathrm{O}_{7}$ at a series of fluences from $1 \times 10^{10}-1 \times 10^{13}$ ions $/ \mathrm{cm}^{2}$. With increasing fluence, the intensity of the Raman bands decreases systematically accompanied by the growth of a broad peak of the amorphous phase of both compounds.

FIG 6. (a) Series of XRD patterns of $\mathrm{Gd}_{2} \mathrm{Ti}_{2} \mathrm{O}_{7}$ and $\mathrm{La}_{2} \mathrm{Ti}_{2} \mathrm{O}_{7}$ as a function of temperature after they had been irradiated at the highest fluence $\left(1 \times 10^{13} \mathrm{ions} / \mathrm{cm}^{2}\right)$. Both compounds recover their original structures. (b) Crystalline fraction deduced from quantitative analysis of XRD patterns as a function of temperature. 
FIG 7. Average track diameters deduced from SAXS measurements as a function of annealing temperature. The irradiation was performed with $2 \mathrm{GeV}$ Ta ions of fluence $5 \times 10^{11}$ ions $/ \mathrm{cm}^{2}$ corresponding to non-overlapping individual tracks. The track signals from SAXS were fitted with the model for hard cylinders including a diameter polydispersity.

FIG 8. Transformation path of $\mathrm{Gd}_{2} \mathrm{Ti}_{2} \mathrm{O}_{7}$ and $\mathrm{La}_{2} \mathrm{Ti}_{2} \mathrm{O}_{7}$ when annealed to $850^{\circ} \mathrm{C}$. 
FIGURES

(a)

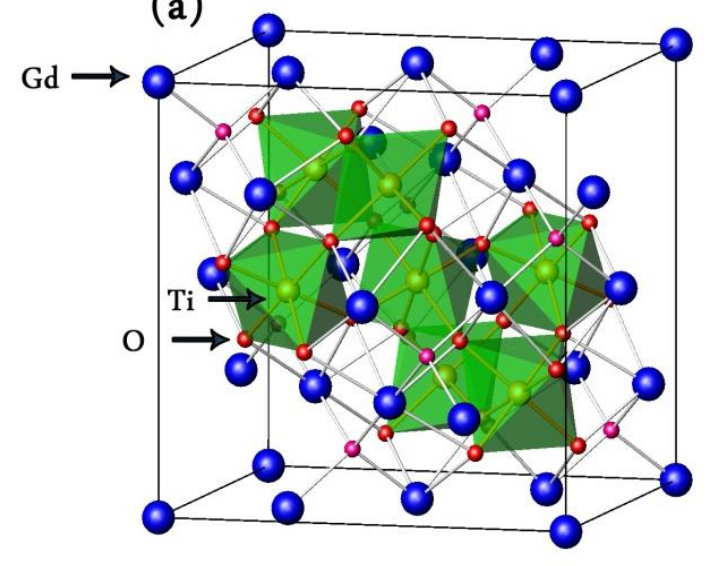

(b)

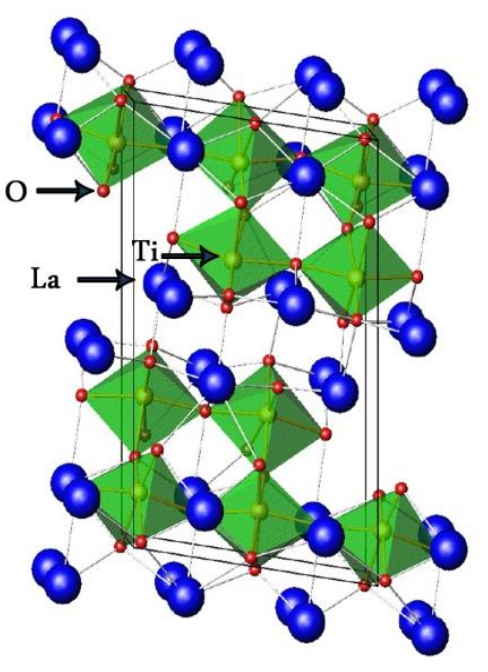

FIG. 1, Park et al., 


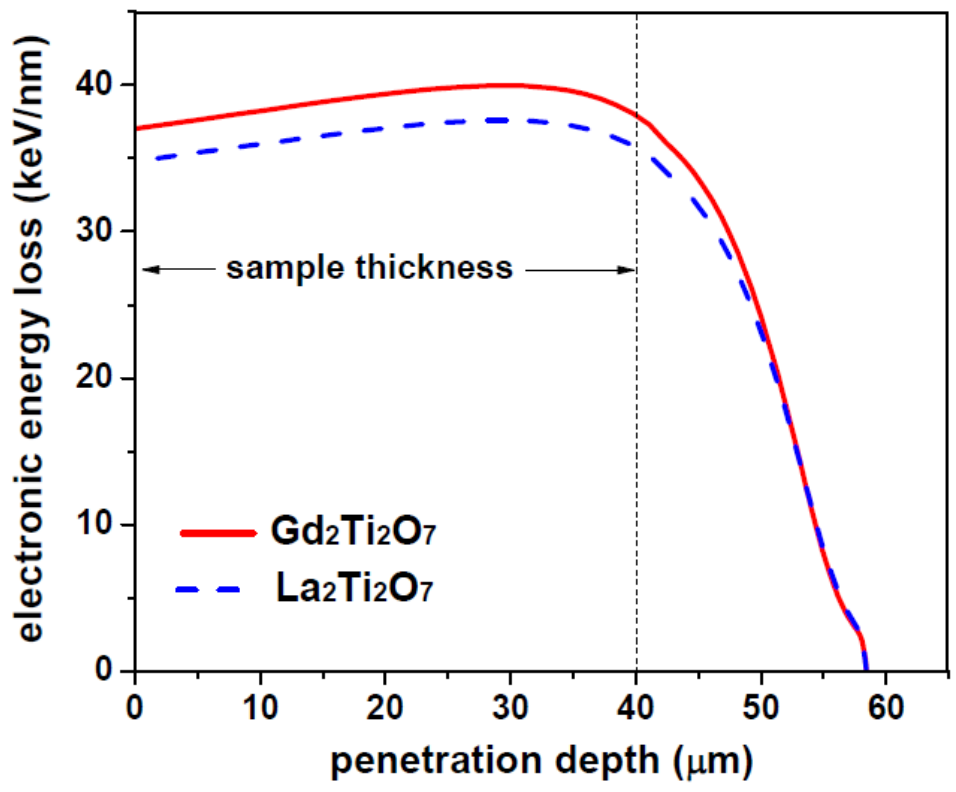

FIG. 2, Park et al., 

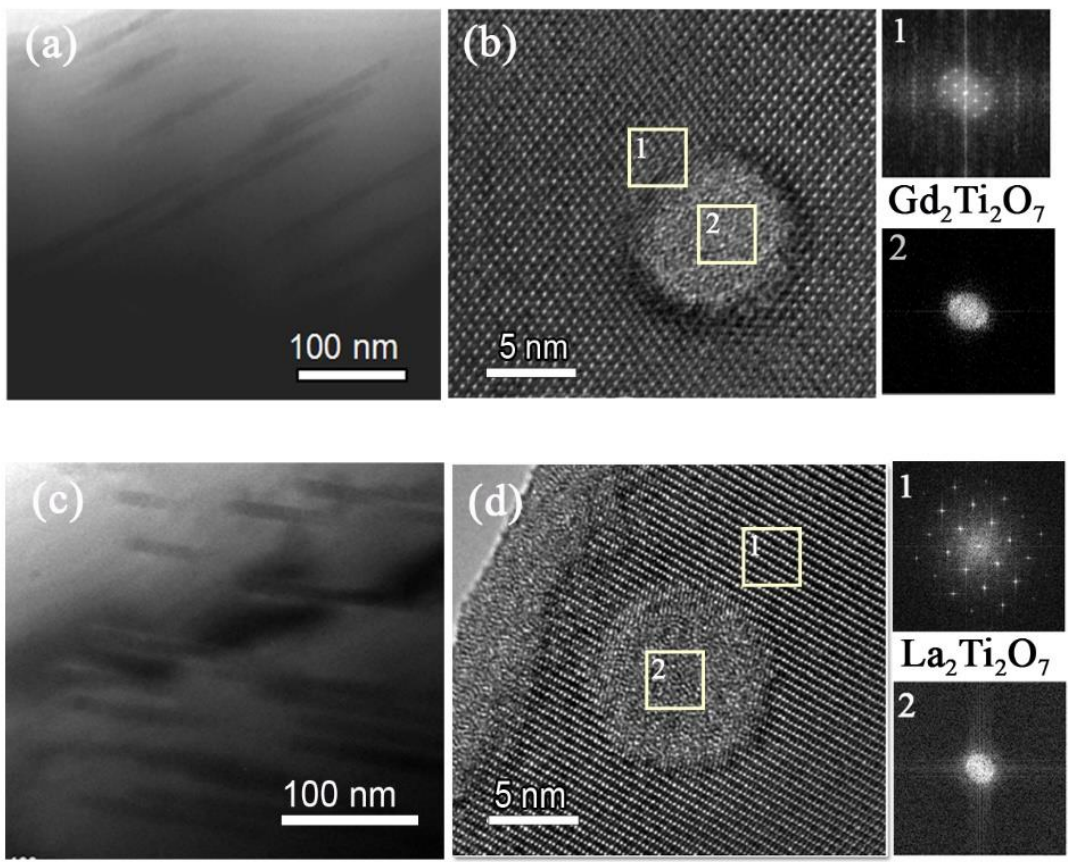

FIG. 3, Park et al., 


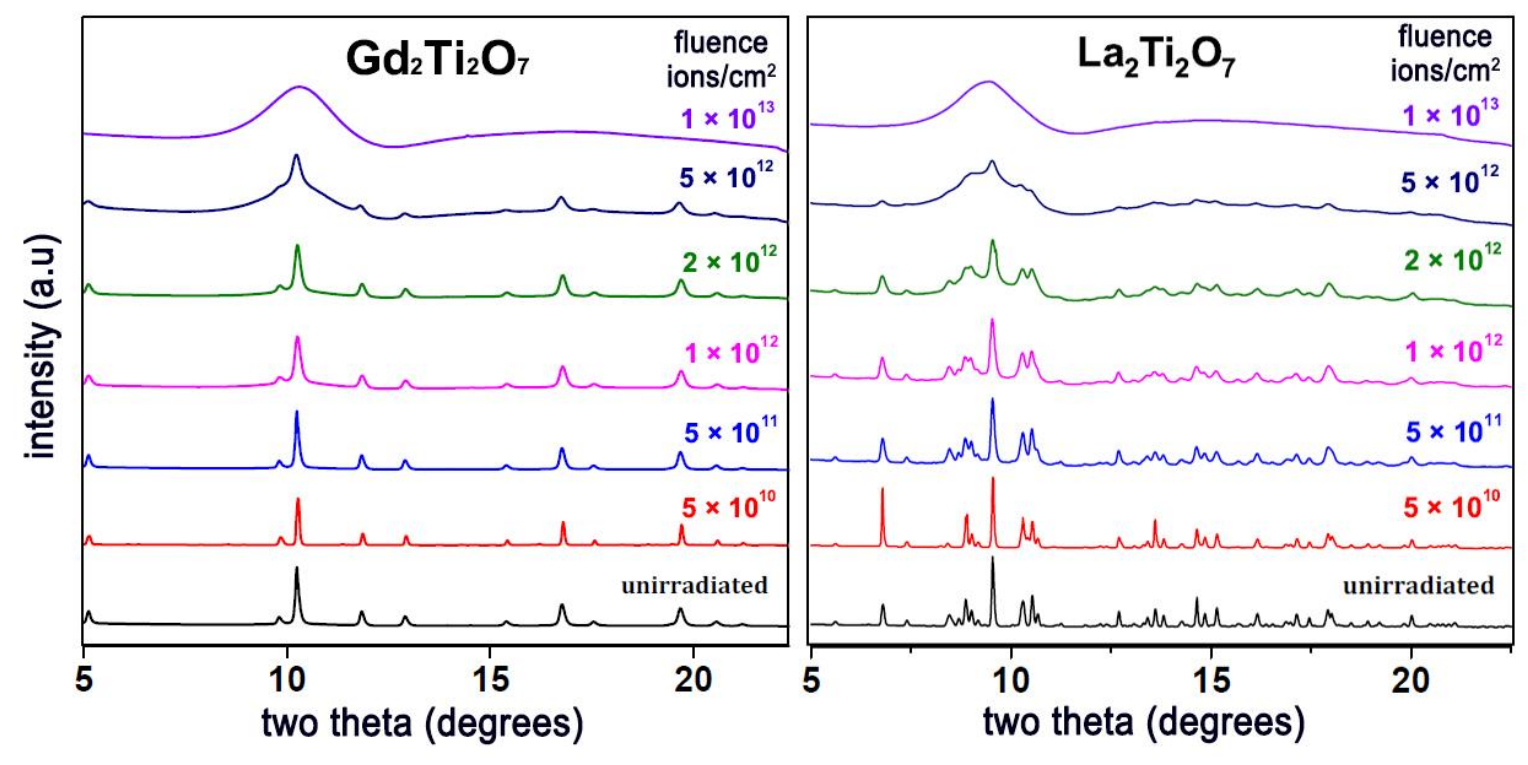

FIG. 4 (a), Park et al., 


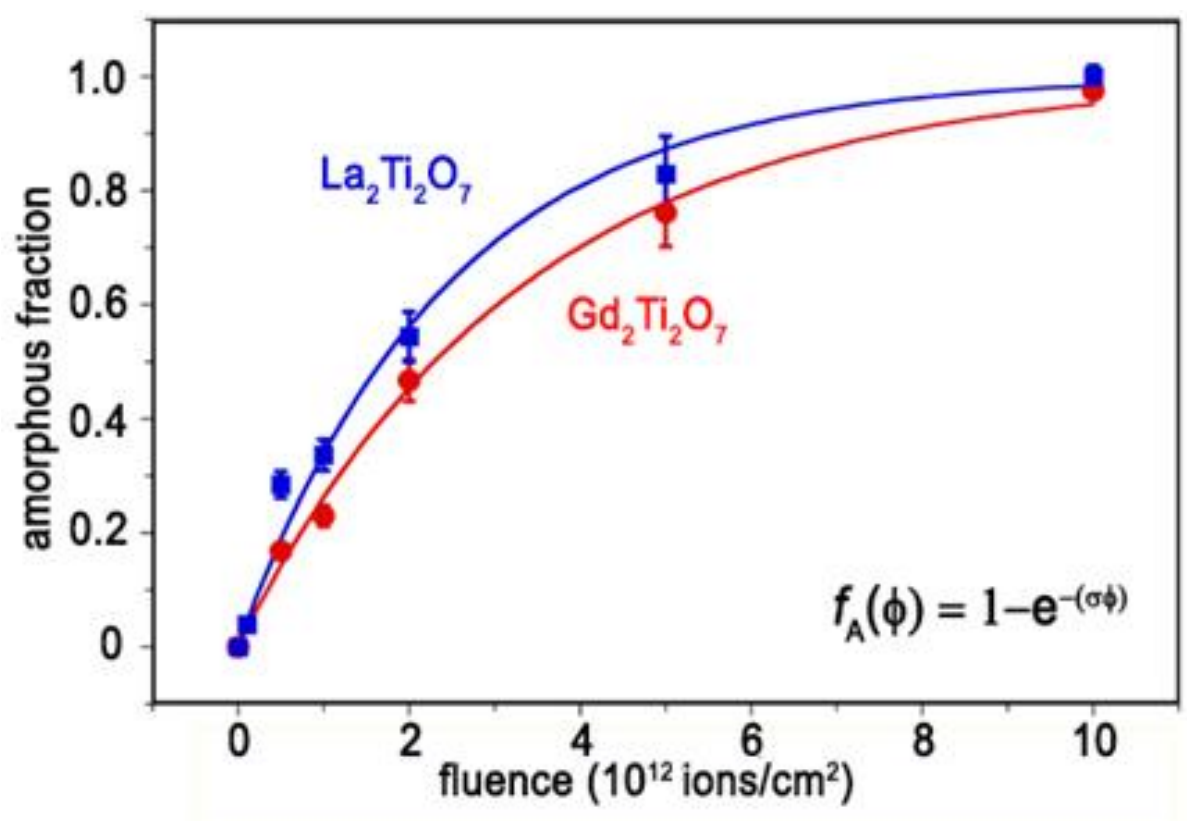

FIG. 4 (b), Park et al., 

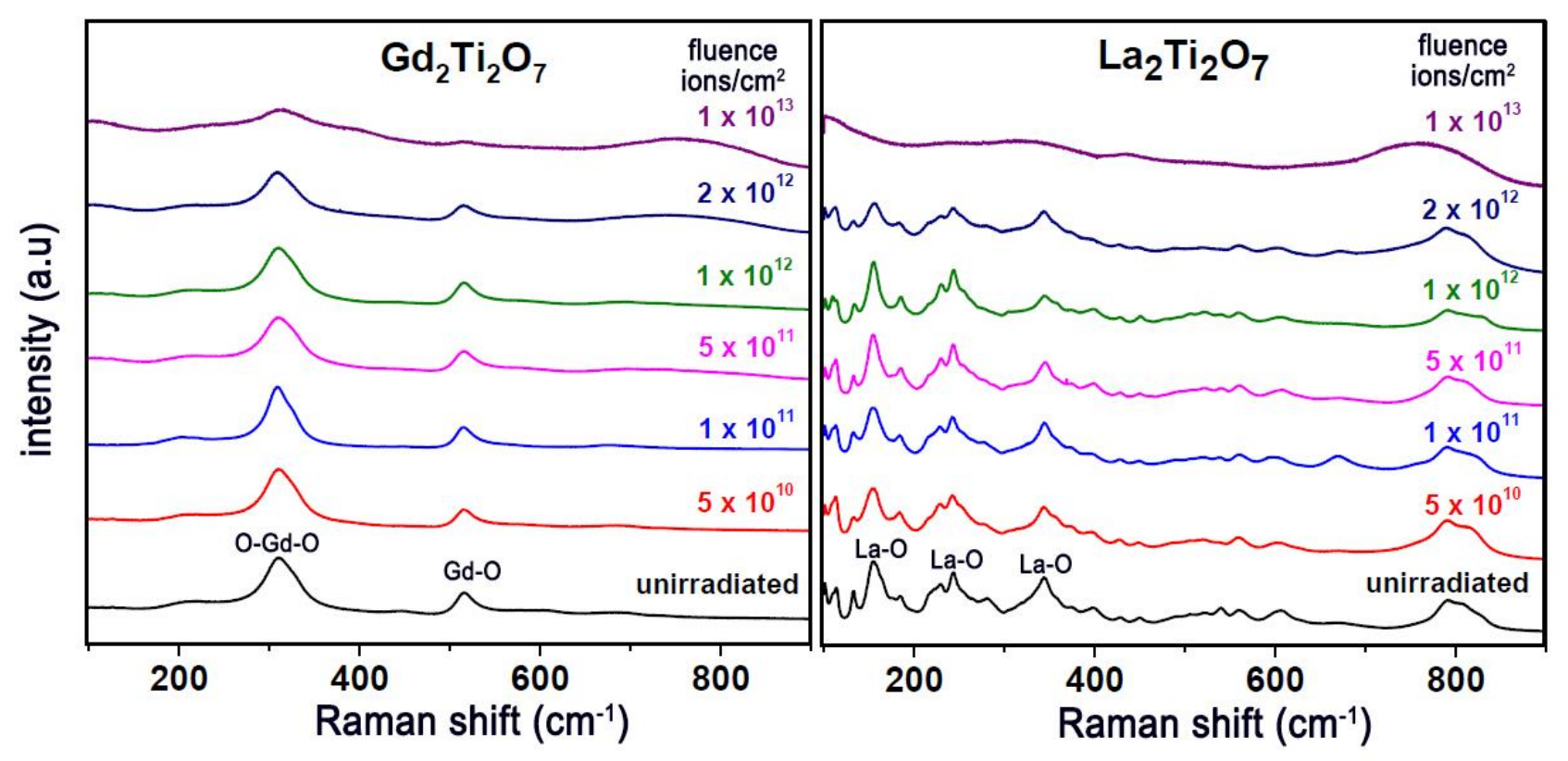

FIG. 5. Park et al., 


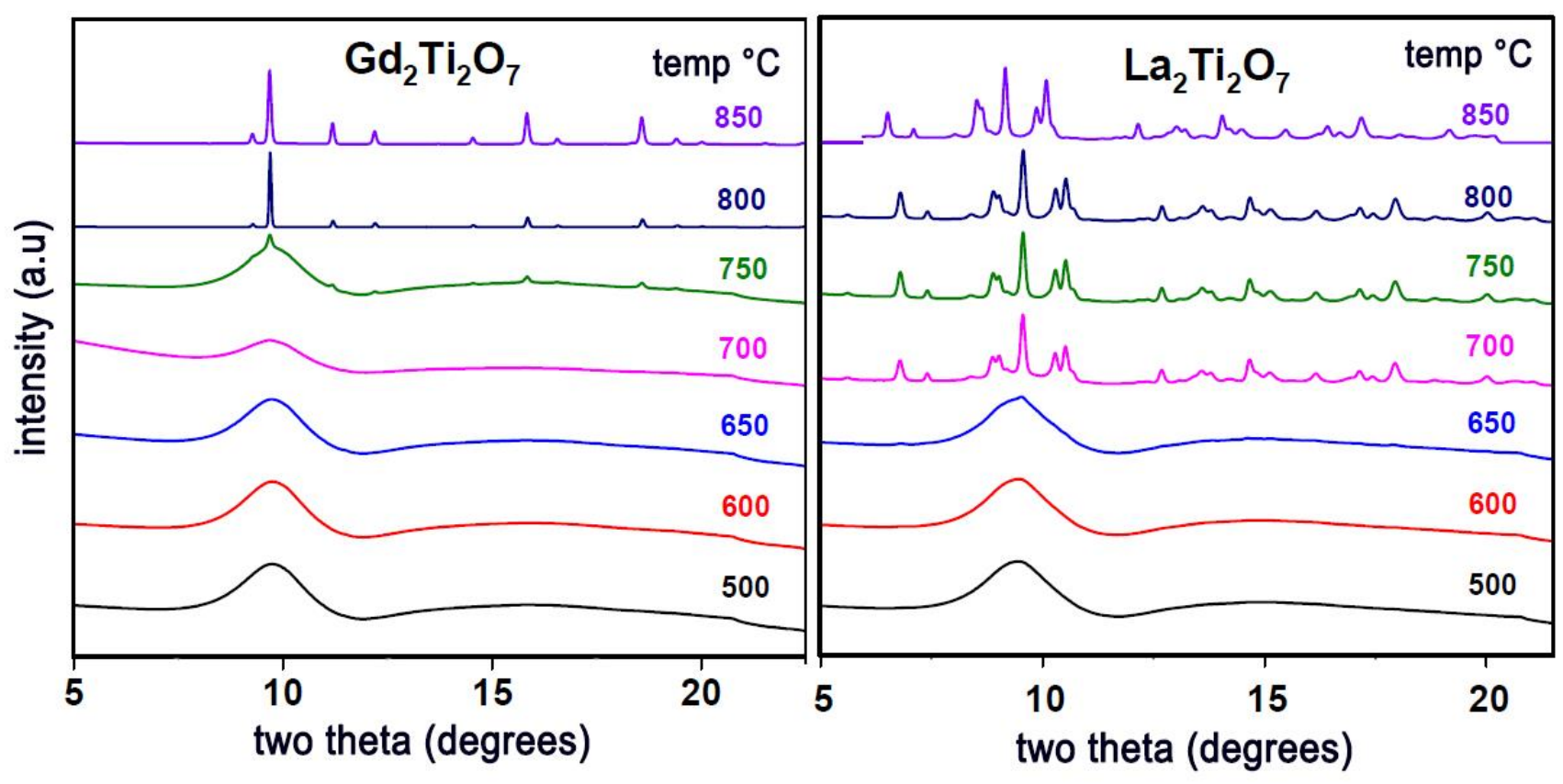

FIG. 6 (a), Park et al., 


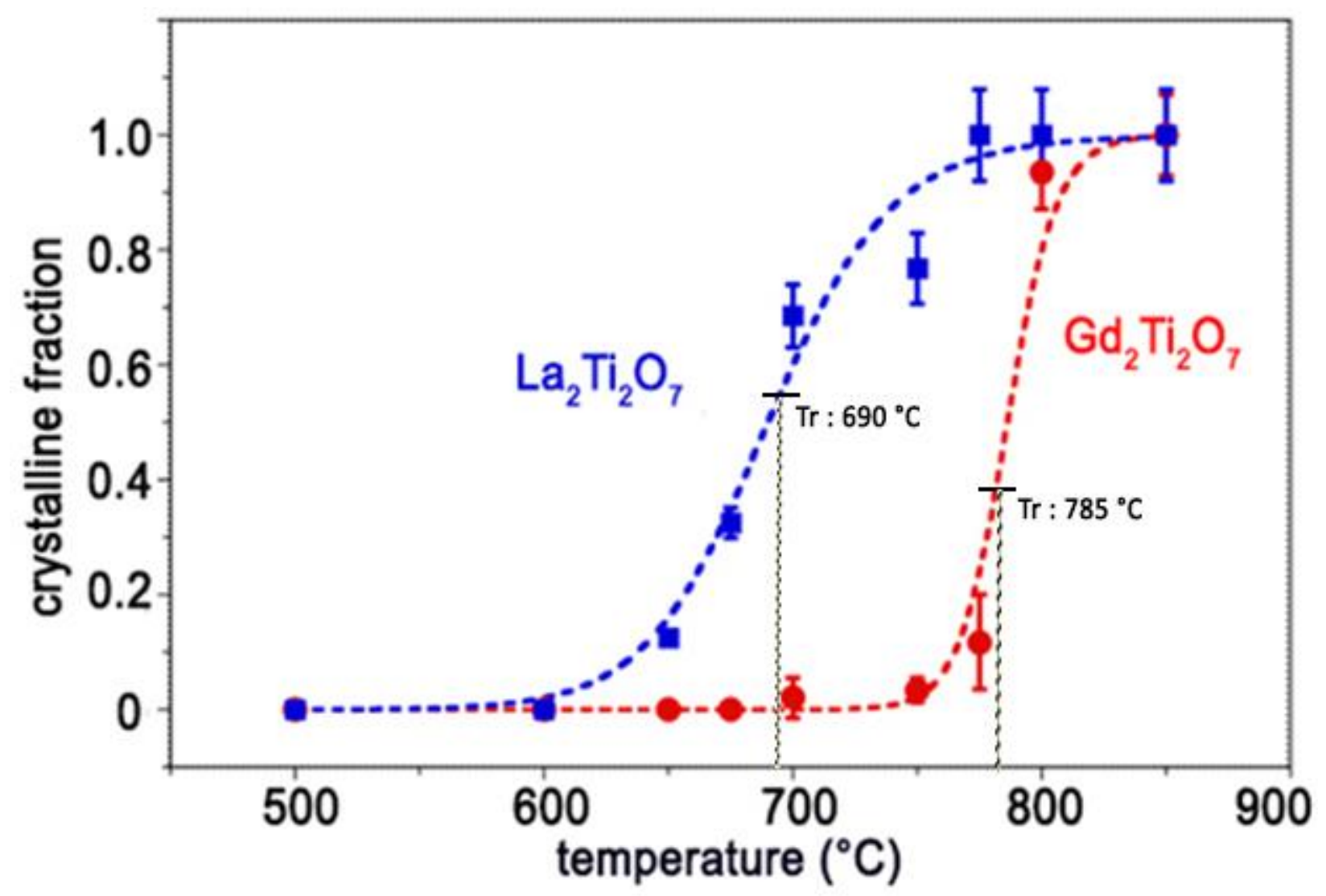

FIG. 6 (b), Park et al., 


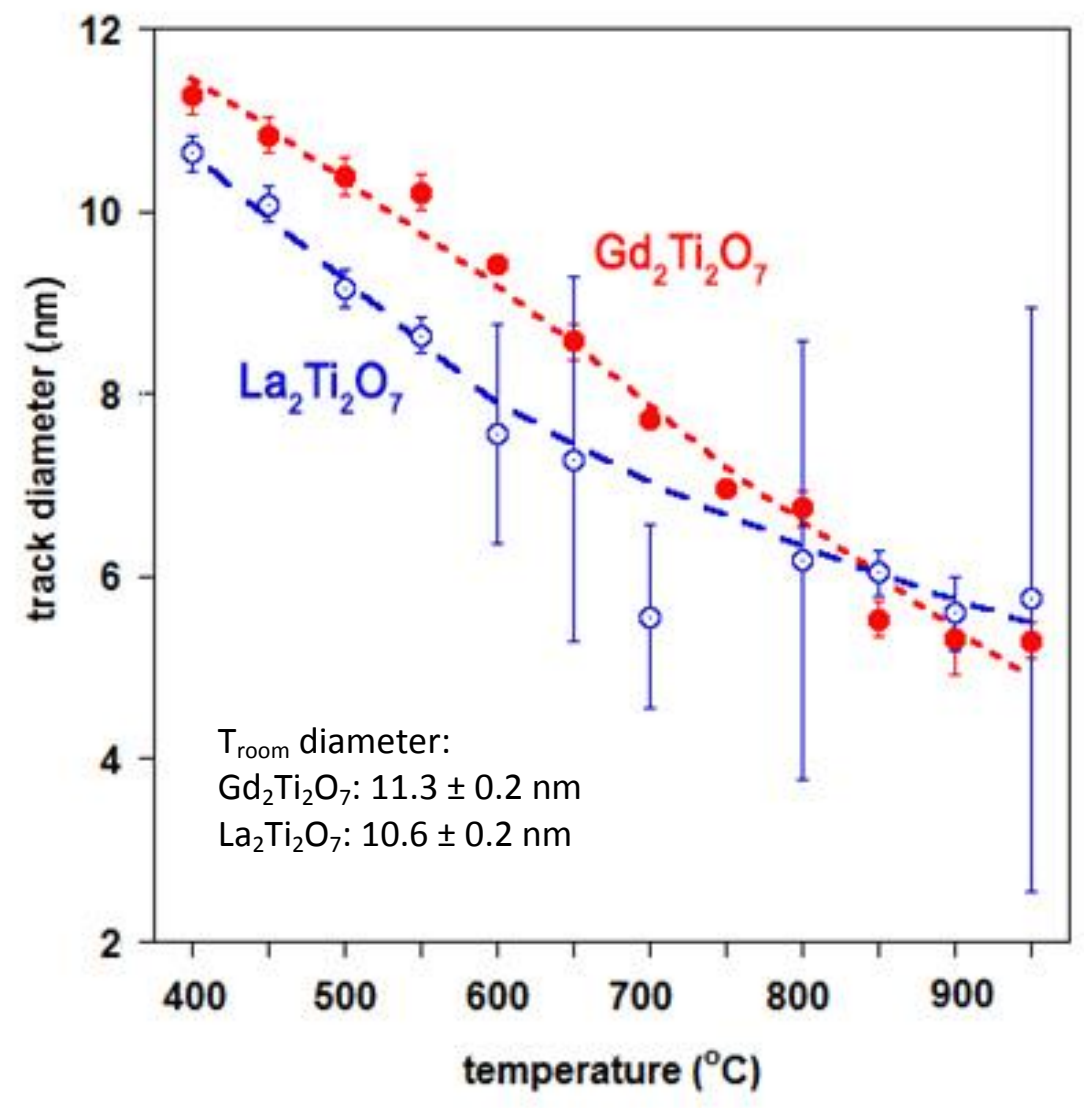

FIG. 7. Park et al., 


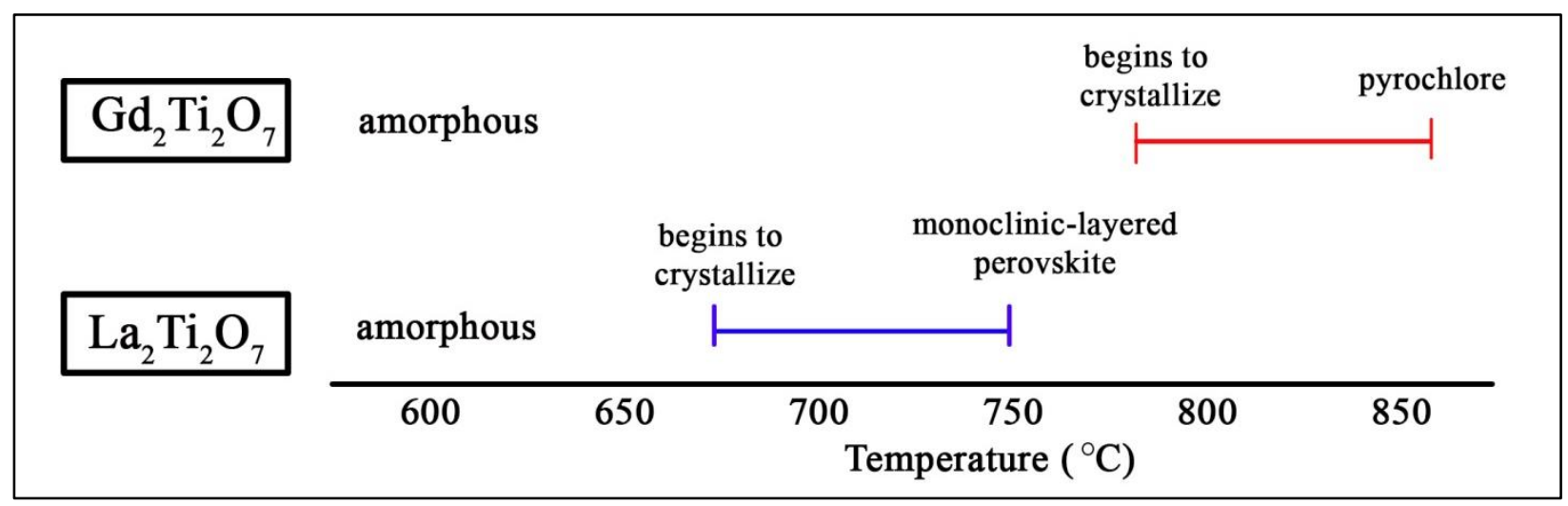

FIG. 8. Park et al., 


\section{TABLE}

Table 1. Tack diameters for $\mathrm{Gd}_{2} \mathrm{Ti}_{2} \mathrm{O}_{7}$ and $\mathrm{La}_{2} \mathrm{Ti}_{2} \mathrm{O}_{7}$ as deduced from different techniques: brightfield and HR-TEM analyze individual ion tracks, XRD data provide diameters due to track overlapping effects from fluence series up to $1 \times 10^{13}$ ions $/ \mathrm{cm}^{2}$, , and SAXS averages track data of large non-overlapping track ensembles.

\begin{tabular}{lccccc}
\hline & $\mathbf{r}_{\mathrm{A}} / \mathbf{r}_{\mathbf{B}}$ & $\begin{array}{c}\text { bright field } \\
(\mathbf{d}=\mathbf{n m})\end{array}$ & $\begin{array}{c}\text { HR-TEM } \\
(\mathbf{d = n m})\end{array}$ & $\begin{array}{c}\text { XRD } \\
(\mathbf{d = n m})\end{array}$ & $\begin{array}{c}\text { SAXS } \\
(\mathbf{d}=\mathbf{n m})\end{array}$ \\
\hline $\mathbf{G d}_{\mathbf{2}} \mathbf{T i}_{\mathbf{2}} \mathbf{O}_{\mathbf{7}}$ & 1.74 & $9.65 \pm 0.5$ & $9.1 \pm 0.6$ & $6.2 \pm 0.7$ & $11.3 \pm 0.2$ \\
$\mathbf{L a}_{\mathbf{2}} \mathbf{T i}_{\mathbf{2}} \mathbf{O}_{\mathbf{7}}$ & 1.92 & $10.8 \pm 0.8$ & $10.2 \pm 0.7$ & $7.2 \pm 0.9$ & $10.6 \pm 0.2$ \\
\hline
\end{tabular}

